\title{
Ressonância magnética na avaliação de enxerto osteocondral autógeno na cartilagem articular de coelhos ${ }^{1}$
}

\author{
Fernando Y.K. Kawamoto ${ }^{2 *}$, Leonardo A.L. Muzzi², Bruno O.A.G. Liria3 ${ }^{3}$, José A.A. \\ Camassa $^{2}$, Stella H. Moreira ${ }^{2}$, Pedro P. Rossignoli ${ }^{2}$ e Ruthnéa A.L. Muzzi ${ }^{2}$
}

\begin{abstract}
Kawamoto F.Y.K., Muzzi L.A.L., Liria B.O.A.G., Camassa J.A.A., Moreira S.H., Rossignoli P.P. \& Muzzi R.A.L. 2017. [Magnetic resonance in the evaluation of autogenous osteochondral graft in articular cartilage of rabbits.] Ressonância magnética na avaliação de enxerto osteocondral autógeno na cartilagem articular de coelhos. Pesquisa Veterinária Brasileira 36(5):502-510. Departamento de Medicina Veterinária, Universidade Federal de Lavras, Câmpus Universitário, Av. Doutor Sylvio Menicucci 1001, Cx. Postal 3037, Kennedy, Lavras, MG 37200-000, Brazil. E-mail: fe.kawamoto@gmail.com

This study aimed to determine the characteristics and applicability of magnetic resonance imaging (MRI) in the evaluation of autogenous osteochondral graft in intact or macerated format, with or without insulin-like growth factor type 1 (IGF-1) used in repair of cartilage lesions induced in rabbits. Nine New Zealand rabbits were used, in which 18 stifle joints underwent grafting procedure in the femoral trochlear groove. These were divided into four groups, referred as intact osteochondral graft + IGF-1 ( $n=5)$, intact osteochondral graft + saline solution $(n=4)$, macerated osteochondral graft + IGF-1 $(n=5)$ and macerated osteochondral graft + saline solution $(n=4)$. Animals were euthanized 12 weeks after surgery and the joints were subjected to MRI using a high magnetic field scanner of 1.5 Tesla. In addition, samples of grafting sites were subjected to anatomopathological examination. The MRI was effective as a noninvasive method to evaluate the repair tissue in osteochondral grafts in articular cartilage of the femur of rabbits by providing complementary data to macroscopic and histological examinations. Through these images and anatomopathological examinations satisfactory results were observed in relation to the repair process of autogenous osteochondral grafts in cartilage of rabbits, regardless of its format or the addition of IGF-1.
\end{abstract}

INDEX TERMS: Magnetic resonance imaging, autogenous osteochondral graft, articular cartilage, insulin-like growth factor I, rabbits.

RESUMO.- Este trabalho teve o objetivo de determinar as características e a aplicabilidade do exame de ressonância magnética na avaliação de enxerto ostecondral autógeno, em formato íntegro ou macerado, associado ou não ao fator de crescimento semelhante à insulina tipo 1 (IGF-1), utilizado no reparo de lesões induzidas na cartilagem articular de coelhos. Foram utilizados 9 coelhos da linhagem Nova Zelândia, em que as 18 articulações fêmoro-tíbio-patelares

\footnotetext{
${ }^{1}$ Recebido em 30 de maio de 2016.

Aceito para publicação em 4 de setembro de 2016.

${ }^{2}$ Departamento de Medicina Veterinária, Universidade Federal de Lavras, Campus Universitário, Av. Doutor Sylvio Menicucci 1001, Cx. Postal 3037, Kennedy, Lavras, MG 37200-000, Brasil. *Autor para correspondência:lalmuzzi@dmv.ufla.br

${ }^{3}$ Ecomed Serviços Médicos em Exames de Imagem, Rua Costa Pereira 125-A, Lavras, MG 37200-000, Brasil.
}

foram submetidas à enxertia osteocondral autógena no sulco troclear femoral. Estas foram divididas em quatro grupos, denominados como enxerto osteocondral íntegro + IGF-1 ( $\mathrm{n}=5)$, enxerto osteocondral íntegro + solução fisiológica $(n=4)$, enxerto osteocondral macerado + IGF-1 $(n=5)$ e enxerto osteocondral macerado + solução fisiológica $(n=4)$. Os animais foram eutanasiados em 12 semanas após a cirurgia e as articulações foram submetidas ao exame de ressonância magnética utilizando um aparelho scanner de 1,5 Tesla de alto campo magnético. Além disso, amostras dos locais de enxertia foram submetidas aos exames anatomopatológicos. 0 exame de ressonância magnética mostrou-se eficaz como um método não invasivo para avaliação do tecido de reparação em enxertos osteocondrais na cartilagem articular do fêmur de coelhos, fornecendo dados complementares aos exames macroscópicos e histológicos. Por 
meio destas imagens e dos exames anatomopatológicos, foram observados resultados satisfatórios em relação ao processo de reparação dos enxertos osteocondrais autógenos na cartilagem de coelhos, independentemente de seu formato ou da adição de IGF-1.

TERMOS DE INDEXAÇÃO: Imagem por ressonância magnética, enxerto osteocondral autógeno, cartilagem articular, fator de crescimento semelhante a insulina tipo 1, coelhos.

\section{INTRODUÇÃO}

A cartilagem articular possui uma capacidade limitada de reparação (Sellers et al. 1997, Martin-Hernandez et al. 2010, Dhollander et al. 2011, Khan et al. 2013, Kim et al. 2013, Liu et al. 2015, Jing et al. 2015), devido ao ambiente avascular, ausência de inervação (Thiede et al. 2012, Mollon et al. 2013), pouca mobilidade dos condrócitos e capacidade reduzida de proliferação dos condrócitos maduros (Nam et al. 2004, Chiang \& Jiang 2009), o que impossibilita a recuperação do tecido cartilaginoso para seu estado original e geralmente resulta no preenchimento do defeito com tecido fibrocartilaginoso (Simank et al. 2004, Singh et al. 2013, Tiwary et al. 2013).

A técnica de enxertia osteocondral de origem autógena possibilita o preenchimento do defeito articular com cartilagem hialina própria e livre de reações imunológicas presentes nos enxertos homólogos (Hattori et al. 2007, Krusche-Mandl et al. 2012, Zak et al. 2014), além disso, permite a criação de uma barreira imediata entre o fluido sinovial e osso subcondral, e a reconstituição da superfície articular e da capacidade de suporte de carga do osso subcondral (Bodo et al. 2004, Fitzpatrick et al. 2010). A restauração do contorno e da congruência articular é desejável na realização do procedimento de enxertia osteocondral, pois influencia de forma direta a função do enxerto e os resultados do tratamento (Cook et al. 2008, Böttcher et al. 2010).

Os esforços para alcançar o reparo adequado das lesões osteocartilaginosas são restritos pela dificuldade de estimular as células residentes a formarem uma nova cartilagem com propriedades semelhantes à original (Madry et al. 2005, Siebert et al. 2006, Araki et al. 2013). A administração exógena de fator de crescimento semelhante a insulina tipo 1 (IGF-1) tem sido relatada como um importante elemento no reparo dessas lesões, ao promover o aumento da atividade mitótica dos condrócitos e a síntese de proteoglicanos e de colágeno do tipo II (Holland et al. 2007, Madry et al. 2010, Orth et al. 2011, Loffredo et al. 2014).

A ressonância magnética (RM) possui grande potencial de análise e monitoramento dos distúrbios articulares. Constitui-se um exame não radio-ionizante e não invasivo de escolha para se avaliar a lesão e os processos de reparação articulares. Permite a visualização detalhada dos tecidos intra-articulares, fornecendo contraste diferenciado entre os tecidos moles em diferentes ponderações de imagem e com capacidade multiplanar (Muglia et al. 2001, Efe et al. 2012, Blackman et al. 2013, Endo et al. 2015). A partir da utilização de técnicas específicas para a região articular, a RM fornece informações sobre as alterações de sinal do tecido cartilaginoso, da morfologia da superfície articular e do osso subcondral (Rodrigues \& Camanho 2010, Kido et al. 2014). Além disso, em tratamentos com enxertos osteocondrais, proporciona a obtenção de dados estruturais importantes a respeito do preenchimento do defeito, da integração do tecido de reparação com a cartilagem circundante e do aspecto da superfície articular (Nho et al. 2008, Battaglia et al. 2011).

O objetivo deste trabalho foi comparar, por meio da avaliação de ressonância magnética, o reparo de lesões induzidas na superfície articular do fêmur de coelhos tratadas com enxerto autógeno íntegro ou macerado, associado ou não ao IGF-1, utilizado no reparo de lesões induzidas na cartilagem articular de coelhos.

\section{MATERIAL E MÉTODOS}

Este projeto de pesquisa foi submetido à Comissão de Ética no Uso de Animais (CEUA/UFLA), Protocolo no 010/11. Foram selecionados 9 coelhos da linhagem Nova Zelândia provenientes de cunicultura regulamentada (Fazenda Experimental Prof. Hélio Barbosa/UFMG), fêmeas, hígidas, com seis meses de idade ao início da pesquisa e peso corporal médio de 4,5 kg. Inicialmente, todos os animais foram submetidos a exame clínico e radiográfico, além de um período de adaptação de 30 dias, para atestar as condições de saúde adequadas. As 18 articulações foram submetidas à enxertia osteocondral autógena no sulco troclear femoral. Estas foram divididas aleatoriamente em quatro grupos, denominados como enxerto osteocondral íntegro + IGF-1 (IGF-1 100 $\mu \mathrm{g}$, Biovision, USA) (INT+IGF/n=5), enxerto osteocondral íntegro + solução fisiológica (INT+FIS/n=4), enxerto osteocondral macerado + IGF-1 (MAC+IGF/n=5) e enxerto osteocondral macerado + solução fisiológica (MAC+FIS /n=4). Para se evitar a interferência nos resultados finais de uma possível absorção e ação sistêmica do fator de crescimento, cinco animais receberam os enxertos sempre associados ao IGF-1 (Grupo INT+IGF em uma articulação e grupo MAC+IGF na articulação contralateral) e quatro animais receberam os enxertos sempre sem o acréscimo do IGF-1 (Grupo INT+FIS em uma articulação e grupo MAC+FIS na articulação contralateral).

A artrotomia fêmoro-tíbio-patelar foi realizada seguindo as recomendações de Madry et al. (2010), por meio de uma incisão parapatelar medial. Com o auxílio de uma trefina manual, colheu-se um cilindro de enxerto osteocondral de $3,0 \mathrm{~mm}$ de diâmetro e $5,0 \mathrm{~mm}$ de profundidade. Este instrumento foi posicionado no centro do sulco troclear, perpendicularmente à superfície articular, tendo como referência o tendão do músculo extensor digital longo. Após a realização dos defeitos e remoção dos cilindros osteocondrais, as articulações foram lavadas com solução fisiológica e o sangramento controlado.

0 enxerto osteocondral obtido em um membro foi utilizado no membro contralateral. Nos animais dos grupos INT+IGF e INT+FIS, os enxertos foram mantidos íntegros e introduzidos nos orifícios ósseos por meio de pressão digital, até a obtenção da oclusão dos defeitos. Nos animais dos grupos MAC+IGF e MAC+FIS, os enxertos foram macerados com auxílio de uma cizalha e introduzidos por meio de pressão digital nos defeitos. Ressalta-se que, antes da introdução dos enxertos, nos grupos INT+IGF e MAC+IGF, o local receptor do enxerto foi enriquecido com a instilação de $0,2 \mathrm{ml}$ $(10 \mu \mathrm{g})$ de IGF-1, e nos grupos INT+FIS e MAC+FIS com 0,2ml de solução fisiológica, com o auxílio de uma pipeta de ponta fina. Em todas as situações, colhetou-se previamente $1 \mathrm{~mL}$ de sangue venoso sem EDTA, para a formação de coágulo. Este coágulo autógeno foi posicionado dentro do defeito após a instilação do IGF-1 ou da solução fisiológica, para posterior oclusão com enxerto macerado ou íntegro. 
A sutura da ferida cirúrgica foi realizada utilizando-se fio absorvível de ácido poliglicólico 3-0, para síntese individualizada da cápsula articular, das fáscias musculares e tecido subcutâneo, em padrão simples contínuo. Por fim, empregou-se o mesmo tipo de fio cirúrgico para a dermorrafia, em padrão intradérmico. No período pós-operatório, foram administrados anti-inflamatório e antibiótico durante três e cinco dias, respectivamente, e não foram utilizadas bandagens nos membros operados. Foi permitido aos animais circular livremente em suas gaiolas e sustentar o peso sobre os membros pélvicos imediatamente após a cirurgia.

Os animais foram eutanasiados após 12 semanas da intervenção cirúrgica. Imediatamente após a eutanásia, as articulações operadas foram submetidas ao exame de RM. A articulação fêmoro-tíbio-patelar foi mantida em extensão na posição craniocaudal. Utilizou-se um aparelho scanner de 1,5 Tesla (T) de alto campo magnético ${ }^{4}$ e uma bobina GP Flex.

As imagens sagitais e coronais em tempo 2 (T2), com supressão de gordura para análise, foram obtidas utilizando uma sequência 2D spin-eco rápida com os seguintes parâmetros: campo de visão $(\mathrm{FOV})=14 \times 14 \mathrm{~cm}$, matriz $=256 \times 192$, espessura do corte $=3 \mathrm{~mm}$, tempo de repetição $(\mathrm{TR})=4300 \mathrm{~ms}$; tempo de eco $(\mathrm{TE})=60 \mathrm{~ms}$; duração da digitalização = 24 minutos e largura de banda $=15.63 \mathrm{~Hz}$.

As imagens da RM foram analisadas e quantificadas a partir de um sistema de pontuação invertida, em que foram avaliadas diversas características do local enxertado e da articulação (Quadro 1). Este sistema foi baseado em cinco categorias específicas, e o resultado final variou de zero ponto (sem alterações) até 10 pontos

\section{Quadro 1. Sistema de pontuação do exame de ressonância magnética para avaliação de enxerto osteocondral}

\begin{tabular}{lc}
\multicolumn{1}{c}{ Categorias } & Pontuação \\
\hline 1. Superfície da cartilagem articular & \\
Regular ou irregularidade discreta & 0 \\
Irregularidade moderada ou acentuada & 1 \\
2. Preenchimento do defeito & 0 \\
Total & 1 \\
Moderado & 2 \\
Discreto ou ausente & \\
3. Edema ósseo na região peri-enxerto & 0 \\
Ausente & 1 \\
Discreto & 2 \\
Moderado & 3 \\
Acentuado & \\
4. Acúmulo de líquido no fundo do enxerto & \\
Ausente & 0 \\
Presente & 1 \\
5. Efusão articular & \\
Ausente & 0 \\
Discreta & 1 \\
Moderada & 2 \\
Acentuada & 3
\end{tabular}

(ausência de reparação associada a complicações concomitantes). Na categoria 1 foi avaliada a regularidade da superfície articular, considerando o tecido enxertado; na categoria 2 analisou-se a efetividade do preenchimento do defeito, ou seja, se o tecido reparador estava no mesmo nível da cartilagem original; na categoria 3 foram avaliadas a presença e a intensidade de edema ósseo na região peri-enxerto; na categoria 4 analisou-se a presença do acúmulo de líquido no fundo do leito receptor do enxerto, que se manifestou como uma região com hiperintensidade de sinal; e na categoria 5 foram observadas a presença e a intensidade da efusão articular.

Posteriormente à realização da RM, as articulações operadas foram dissecadas e submetidas ao exame anatomopatológico.

\footnotetext{
${ }^{4} \mathrm{GE}$, Signa LX 1.5T, USA.
}

Realizou-se a avaliação macroscópica do local da enxertia e da região adjacente, assim como da cápsula articular e do líquido sinovial. Foram efetuadas secções longitudinais dos côndilos femorais no sentido distal-proximal e médio-lateral, englobando o defeito, a cartilagem adjacente e o osso subcondral subjacente, as quais foram fixadas em formalina tamponada e descalcificadas. Após o período de descalcificação, realizou-se uma secção axial no centro do local da enxertia, dividindo-se a região enxertada ao meio, o que permitiu a análise macroscópica e microscópica do tecido neoformado que preencheu o defeito. Secções seriadas de $4 \mu \mathrm{m}$, a partir da região central do leito receptor foram processadas para exame histológico e coradas pela técnica de hematoxilina e eosina.

Para comparação entre os grupos experimentais no exame de ressonância magnética, os dados foram submetidos à análise não paramétrica por meio do teste de Kruskal-Wallis. No caso de significância, após o ranqueamento dos casos, as médias ranqueadas foram comparadas por meio do teste de Duncan. Os dados das variáveis foram apresentados utilizando-se a mediana, citando a diferença estatística quando houver. Em todos os testes, sempre foi considerado o nível de significância de $\mathrm{p} \leq 0,05$. Todo procedimento estatístico foi realizado no programa SPSS 16.0.

\section{RESULTADOS}

As imagens da RM das articulações operadas no plano médio-sagital, com ênfase no local enxertado, possibilitaram a visualização da relação entre a cartilagem articular original e o tecido neoformado, além da avaliação da região da superfície articular e do osso subcondral. Após a avaliação e pontuação dos locais de enxertia, constatou-se que não houve diferença significativa entre os grupos estudados

Quadro 2. Medianas e distância interquartílica (DI) da pontuação total obtida ao exame de ressonância magnética (RM) para avaliação de enxerto osteocondral

\begin{tabular}{cc}
\hline Grupos Experimentais & Escore total pela RM \\
\hline Grupo 1 & $2(\mathrm{DI}=4)$ \\
Grupo 2 & $1,5(\mathrm{DI}=1)$ \\
Grupo 3 & $3(\mathrm{DI}=4)$ \\
Grupo 4 & $2(\mathrm{DI}=2)$
\end{tabular}

Grupo 1. Enxerto osteocartilaginoso íntegro associado ao IGF-1, Grupo 2. Enxerto osteocondral íntegro associado à solução fisiológica, Grupo 3. Enxerto osteocondral macerado associado ao IGF-1 e Grupo 4. Enxerto osteocondral macerado associado à solução fisiológica. Obs: Valores menores indicam melhores avaliações. Não houve diferença significativa entre os grupos estudados.

Quadro 3. Medianas e distância interquartílica (DI) da pontuação obtida em cada uma das categorias de avaliação ao exame de ressonância magnética (RM) para avaliação de enxerto osteocondral

\begin{tabular}{lccccc}
\hline Grupos & \multicolumn{5}{c}{ Escore de avaliação pela RM } \\
\cline { 2 - 6 } & $\begin{array}{c}\text { Superfície } \\
\text { articular }\end{array}$ & $\begin{array}{c}\text { Preenchimen- } \\
\text { to do defeito }\end{array}$ & $\begin{array}{c}\text { Edema } \\
\text { ósseo }\end{array}$ & $\begin{array}{c}\text { Acúmulo } \\
\text { de líquido }\end{array}$ & $\begin{array}{c}\text { Efusão } \\
\text { articular }\end{array}$ \\
\hline Grupo 1 & $0(\mathrm{DI}=0)$ & $0(\mathrm{DI}=2)$ & $1(\mathrm{DI}=1)$ & $1(\mathrm{DI}=1)$ & $0(\mathrm{DI}=1)$ \\
Grupo 2 & $0(\mathrm{DI}=0)$ & $0(\mathrm{DI}=0)$ & $1(\mathrm{DI}=1)$ & $1(\mathrm{DI}=1)$ & $1(\mathrm{DI}=0)$ \\
Grupo 3 & $0,5(\mathrm{DI}=1)$ & $0(\mathrm{DI}=1)$ & $1(\mathrm{DI}=1)$ & $0,5(\mathrm{DI}=1)$ & $0(\mathrm{DI}=1)$ \\
Grupo 4 & $0(\mathrm{DI}=0)$ & $0(\mathrm{DI}=0)$ & $1(\mathrm{DI}=1)$ & $0(\mathrm{DI}=1)$ & $0,5(\mathrm{DI}=1)$
\end{tabular}

Grupo 1. Enxerto osteocartilaginoso íntegro associado ao IGF-1, Grupo 2. Enxerto osteocondral íntegro associado à solução fisiológica, Grupo 3. Enxerto osteocondral macerado associado ao IGF-1 e Grupo 4. Enxerto osteocondral macerado associado à solução fisiológica. Obs: Valores menores indicam melhores avaliações. Não houve diferença significativa entre os grupos estudados. 
$(p>0,05)$, tanto na pontuação total (Quadro 2) quanto na pontuação das categorias avaliadas (Quadro 3).

No exame de RM foram observadas as características específicas relacionadas aos grupos estudados de enxertia osteocondral. No grupo INT+IGF, uma das articulações não apresentou qualquer alteração no local enxertado e na região peri-enxerto. Em duas articulações foram observados edema ósseo discreto e presença mínima de líquido na região do fundo do leito receptor. Nas duas articulações restantes deste grupo, uma exibiu superfície articular discretamente irregular, com preenchimento local moderado, e efusão articular e edema ósseo discretos; e a outra demonstrou preenchimento local discreto, edema ósseo moderado, presença de líquido no fundo da região receptora e efusão articular (Fig.1).

No grupo INT+FIS, todas as articulações apresentaram preenchimento total no local da enxertia, superfície articular regular ou com discreta irregularidade. Três articulações apresentaram edema ósseo discreto, e a outra demonstrou edema ósseo e efusão articular discretamente aumentados.
Em relação ao grupo MAC+IGF, uma das articulações avaliadas não apresentou qualquer alteração no local enxertado e na região peri-enxerto, e uma outra articulação demonstrou edema ósseo e efusão articular discretos. Nos outros exemplares, a superfície era discretamente irregular, com edema ósseo discreto e presença de líquido no fundo da região do enxerto, sendo que o preenchimento do defeito demonstrava-se moderado em um deles (Fig.2).

No grupo MAC+FIS, todas as articulações apresentavam a superfície articular regular e adequado preenchimento do local enxertado. Em três articulações foram observados edema ósseo e efusão articular discretos, e uma delas demonstrou edema ósseo moderado e presença de líquido no fundo do leito receptor.

$\mathrm{Na}$ avaliação macroscópica, em nenhuma articulação foi observada a presença de alterações degenerativas. Não houve diferença significativa $(\mathrm{p}>0,05)$ entre os grupos pesquisados em relação aos aspectos macroscópicos dos tecidos de reparação. De maneira geral, a superfície do enxerto apresentava-se regular ou com fibrilações discretas a moderadas, a coloração do tecido neoformado variou do

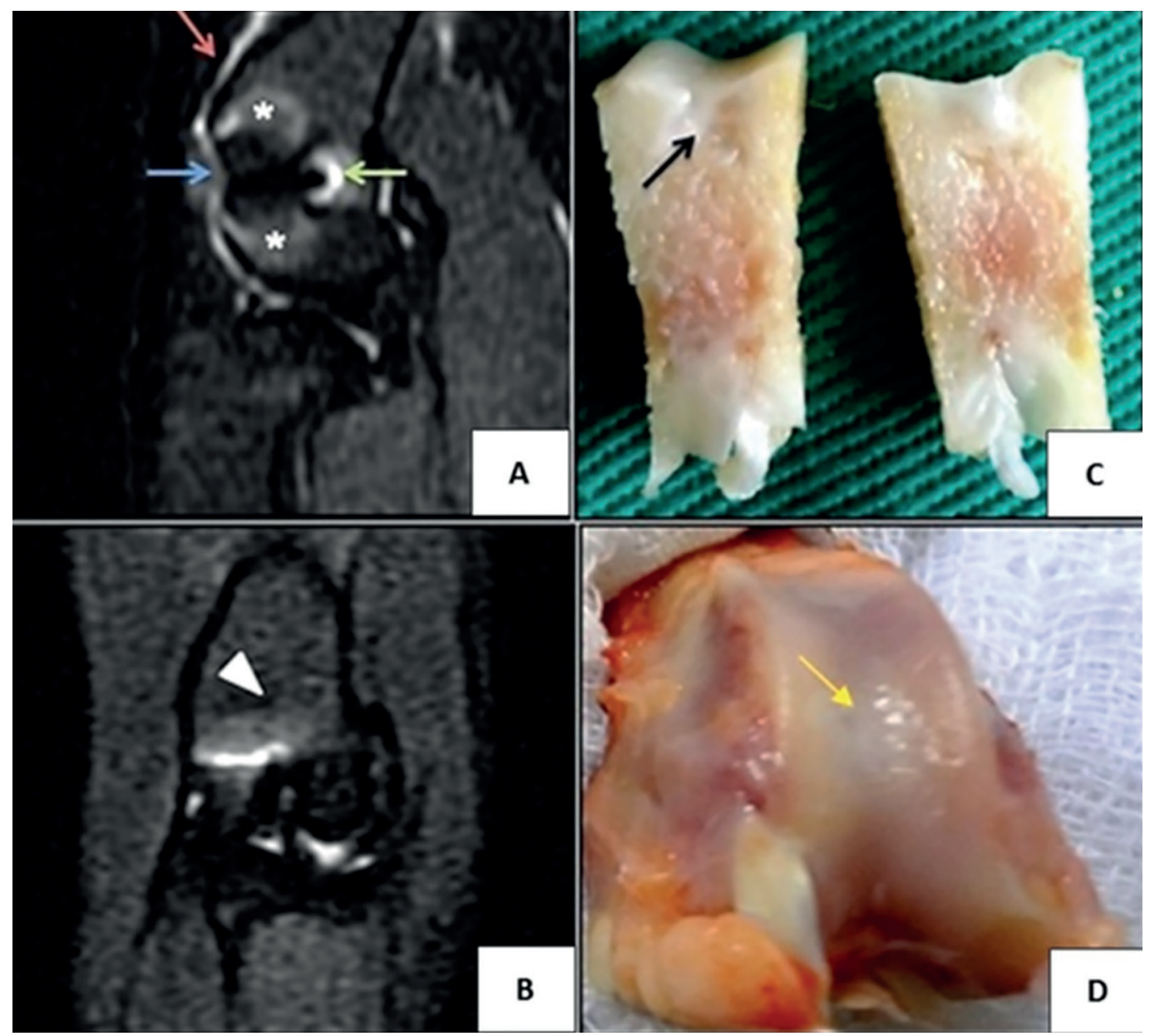

Fig.1. (A,B) Imagens da ressonância magnética obtidas com aparelho de 1,5 Tesla ponderadas em T2 e (C,D) imagens macroscópicas de articulações fêmoro-tíbio-patelares de coelho submetidas à enxertia osteocondral íntegra associada ao IGF-1. (A) Reconstrução sagital demonstrando uma descontinuidade na superfície articular (seta azul), edema ósseo (asteriscos), efusão articular (seta vermelha) e líquido no fundo do leito receptor do enxerto (seta verde). (B) Reconstrução coronal com delimitação discreta da superfície do local de enxertia (ponta de seta). (C) Aspecto macroscópico da secção central no defeito, notar descontinuidade na superfície do tecido de reparação (seta) e ausência de alterações visíveis na região de osso subcondral. (D) Aspecto macroscópico do tecido de reparação formado na superfície do local de enxertia (seta amarela), sem alterações. 


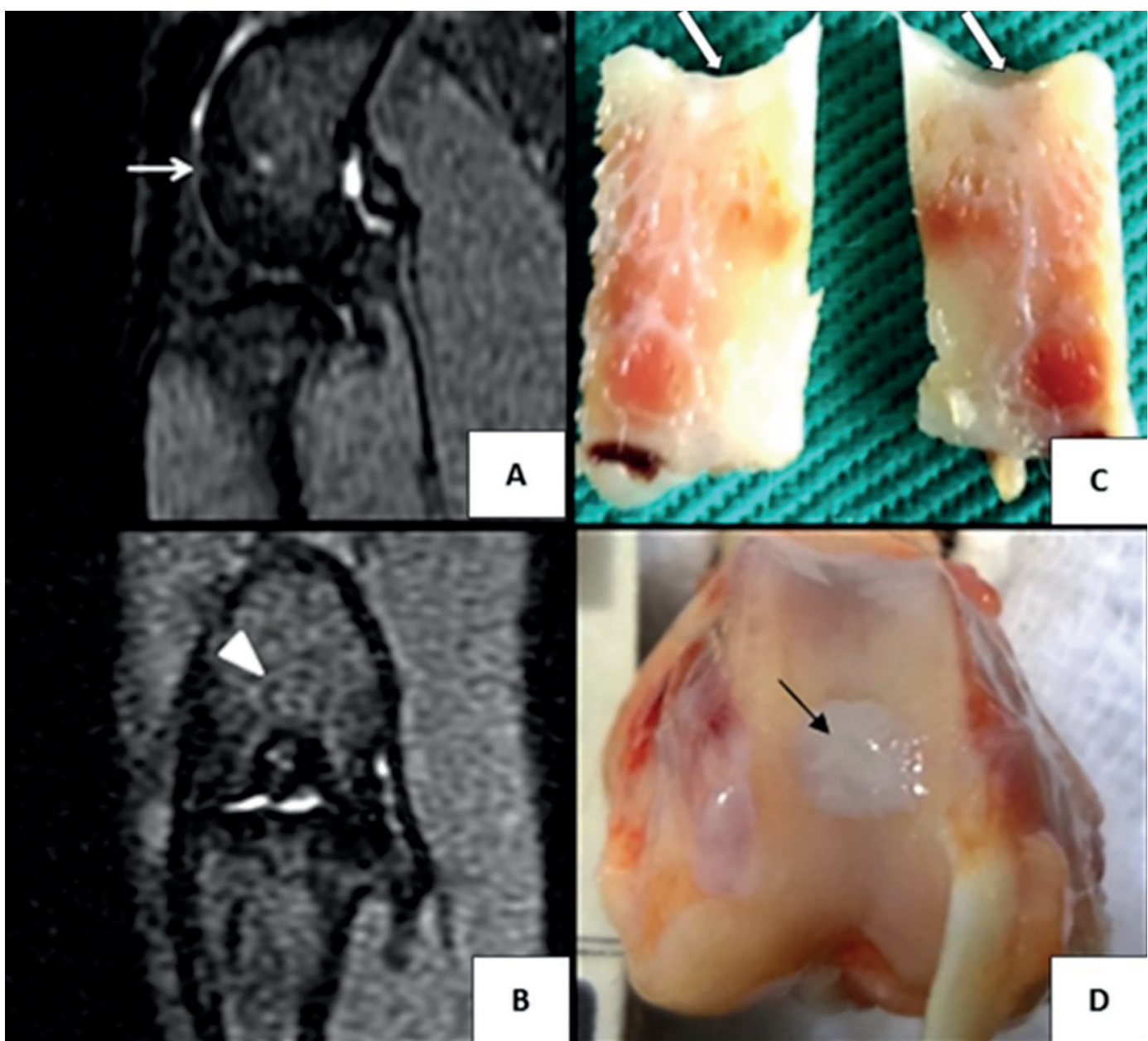

Fig.2. (A,B) Imagens da ressonância magnética obtidas com aparelho de 1,5 Tesla ponderadas em T2 (C,D) imagens macroscópicas de articulações fêmoro-tíbio-patelares de coelho submetidas à enxertia osteocondral macerada associada ao IGF-1. (A) Reconstrução sagital demonstrando a superfície articular regular e bem preenchida no local enxertado (seta), com edema ósseo e efusão articular mínimos. (B) Reconstrução coronal com delimitação discreta da superfície do local de enxertia (ponta de seta). (C) Aspecto macroscópico da secção central no defeito, notar superfície do tecido de reparação preenchido e regular (seta), com ausência de alterações visíveis na região de osso subcondral. (D) Aspecto macroscópico do tecido de reparação formado na superfície do local de enxertia (seta).

translúcido à coloração normal da cartilagem hialina, independentemente do grupo. Todas as amostras apresentaram o defeito preenchido por tecido de reparação nivelado com a cartilagem original. Nos grupos controles sem adição de IGF-1, com enxerto íntegro ou macerado, frequentemente as bordas encontravam-se demarcadas. Contudo, nos grupos com adição de IGF-1, com enxerto íntegro ou macerado, grande parte dos exemplares apresentava completa integração do tecido reparador com a cartilagem original.

$\mathrm{Na}$ avaliação histológica (Fig.3), não houve diferença significativa $(p>0,05)$ entre os grupos pesquisados em relação aos aspectos microscópicos dos tecidos de reparação. De forma geral, o preenchimento total da superfície ocorreu em quase todos os casos, sendo constituído em sua maior parte por cartilagem hialina ou, menos frequentemente, por fibrocartilagem. Foram observados resquícios de tecidos ósseos e cartilaginosos, entremeados na região de cartilagem articular ou de osso subcondral, principalmente nas amostras dos grupos com enxerto macerado. 0 local de integração das bordas apresentava-se adequado, mas com hipocelularidade em alguns casos. Em geral, algu- mas das alterações observadas ao exame de RM não se correlacionaram diretamente com os achados nas avaliações macroscópica e histológica.

\section{DISCUSSÃO}

0 equipamento de RM utilizado neste estudo foi de 1,5 T e, apesar do tamanho reduzido das articulações dos animais utilizados, o que pode comprometer a captação e a qualidade das imagens, as informações diagnósticas fornecidas foram relevantes e precisas. Geralmente, na rotina clínica e experimental veterinária, os aparelhos de RM possuem de 1,5 a 3 T, sendo este o parâmetro utilizado para a resolução espacial máxima, permitindo o exame inclusive de animais de grande porte (Goebel et al. 2012). No estudo realizado por Pujol et al. (2011), fez-se a avaliação anatômica da articulação do joelho em cães utilizando um equipamento de RM de 0,2 T de baixo campo, e os autores relataram que a cartilagem articular não foi claramente observada em nenhuma articulação.

Um fator que contribuiu positivamente no atual estudo foi a utilização de um aparelho de alto campo magnético. Estes equipamentos fornecem uma resolução espacial me- 


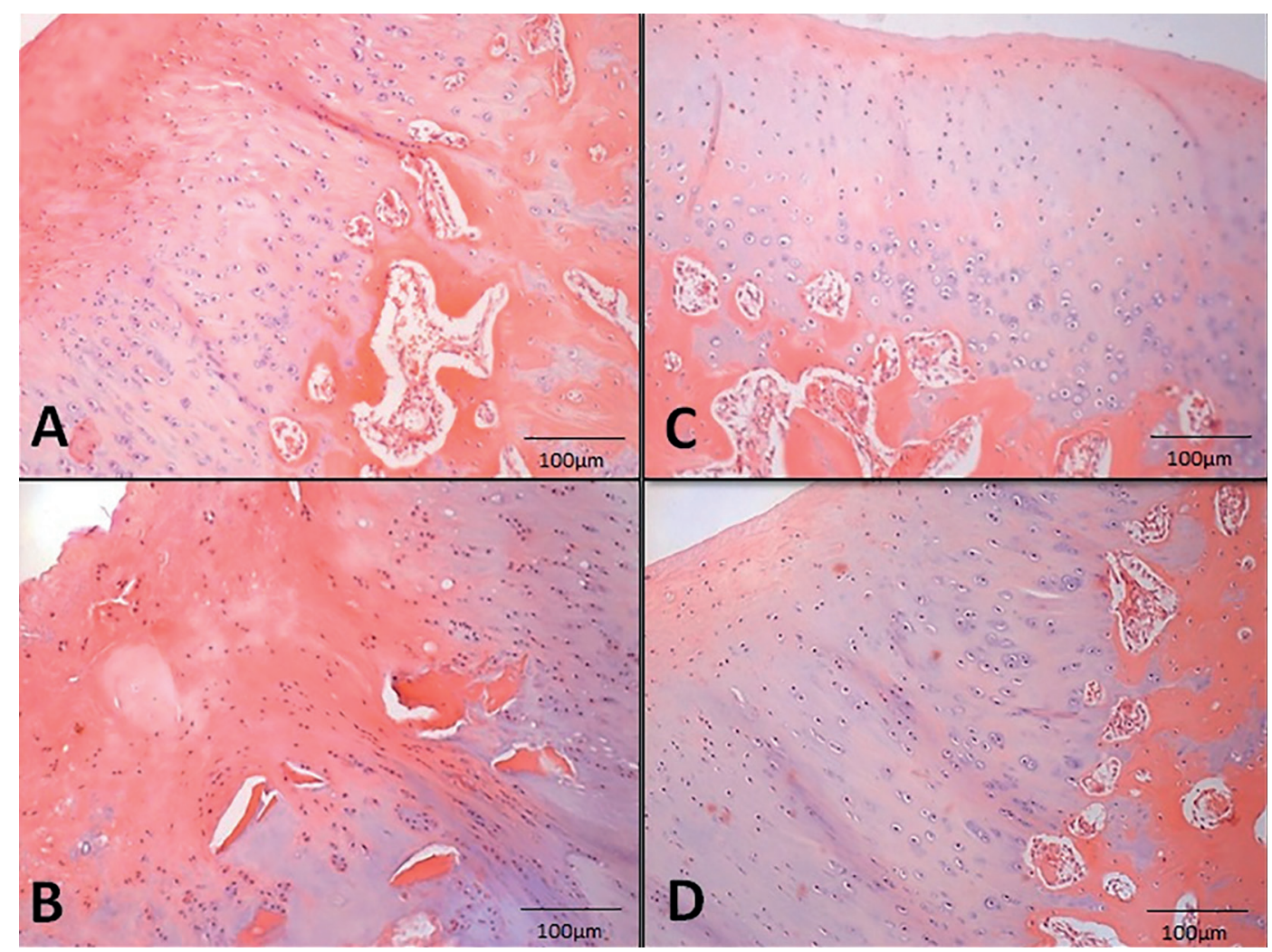

Fig. 3. (A) Imagens histológicas da superfície articular e osso subcondral da região de enxertia osteocondral na tróclea femoral de coelho, coradas com hematoxilina e eosina, após 12 semanas da cirurgia. Enxerto íntegro + IGF-1. (B) Enxerto íntegro + solução fisiológica. (C) Enxerto macerado + IGF-1. (D) Enxerto macerado + solução fisiológica. Obj.10x.

lhor, com uma boa relação sinal-ruído dentro de um tempo relativamente curto (Goebel et al. 2012). De acordo com Trattnig et al. (2011), para a obtenção de uma imagem de melhor qualidade do tecido de reparação da cartilagem articular é recomendado um aparelho de alto campo, possuindo 1,5 T ou mais. Em contrapartida, os equipamentos de alto campo apresentam maior custo e podem exibir artefatos de imagem. No trabalho realizado por Van Caelenberg et al. (2011), em que foi realizada a descrição anatômica dos tecidos moles da cabeça de coelhos normais, foi utilizado um equipamento de $0,2 \mathrm{~T}$ de baixo campo. Os autores citaram que, embora se tenha conseguido imagens de boa qualidade, foi gasto um tempo relativamente longo para a aquisição de todas as sequências necessárias ao exame, com cerca de 30 minutos de duração. Na atual pesquisa, com a utilização do aparelho de 1,5 T de alto campo, o tempo total para a aquisição das imagens foi de aproximadamente 20 minutos por articulação e, em apenas uma amostra, foi verificada a formação de um discreto artefato de imagem.

Para avaliação neste trabalho, as imagens da série sagital T2 com supressão de gordura foram utilizadas como parâmetro, pois evitaram o sinal intenso da gordura na medula óssea e subcutâneo, e dessa forma permitiram a melhor visualização das estruturas ósseas e realçaram as imagens das cartilagens articulares, além de possibilitar a identificação de edema ósseo e outros distúrbios articulares. Assim, a RM destacou-se como uma importante ferramenta diagnóstica, uma vez que permitiu a detecção de alterações no processo de reparação dos enxertos osteocondrais. A RM é reconhecida como um método não invasivo para examinar patologias articulares e uma referência efetiva para avaliar a reparação em cartilagens (Goebel et al. 2012, Rodríguez-Merchán 2012, Bekkers et al. 2013, Endo et al. 2015, Obara et al. 2015). Além disso, a RM também pode ser útil na identificação de lesões ósseas ocultas à radiografia convencional, incluindo as contusões ósseas e fraturas osteocondrais, que representam sítios de hiperemia, edema ou hemorragia óssea (Grossi et al. 2001, Kido et al. 2014).

No presente estudo, notou-se a importância das informações fornecidas pelas imagens da RM, que complementaram com dados não observados nas avaliações macro e microscópicas, principalmente quanto ao edema ósseo e presença de líquido no fundo do leito receptor. Assim, estas imagens podem apresentar dados precisos do tecido avaliado, pois podem atingir tamanhos de voxel muito pequenos, de 120 micrômetros. Além do mais, a reconstrução multiplanar permite a análise do tecido de reparação em três planos diferentes, o que é raramente possível com cortes histológicos (Goebel et al. 2012). Em estudos de enxertia osteocartilaginosa, a RM pode fornecer informações a respeito do estado do osso subcondral, da incorporação do enxerto, da espessura da cobertura cartilaginosa e da congruência da superfície articular. E, dependendo da amostra e do tipo de pesquisa, variáveis como osteólise circundante aos implantes bioabsorvíveis, reação sinovial inflamatória e alteração na placa do osso subcondral podem ser identificadas por este exame (Trattnig et al. 2011).

De maneira geral, em todos os grupos avaliados, obser- 
vou-se resultado satisfatório em relação aos enxertos osteocondrais de acordo com as imagens da RM, sendo observada superfície regular e preenchida, e sinal isointenso em relação ao tecido original. No entanto, em alguns casos, os resultados alterados estavam relacionados com a presença de líquido no fundo da região receptora, maior quantidade de edema ósseo e efusão articular, associados ou não ao preenchimento do defeito abaixo do nível da superfície articular adjacente. Ao exame de imagem, considerou-se que grande parte das amostras demonstrou incorporação do tecido enxertado em 12 semanas após a cirurgia, independentemente do grupo avaliado. Em concordância, algumas pesquisas com RM em animais demonstraram que o enxerto osteocondral pode apresentar incorporação óssea entre 6 e 14 semanas após o procedimento (Trattnig et al. 2011).

Existe uma relação mecânica e biológica íntima entre a cartilagem articular e o osso subcondral. 0 comprometimento do osso subcondral formado durante o processo de remodelação pode alterar a qualidade da cartilagem sobreposta (Bellido et al. 2011, Heir et al. 2012, Schub et al. 2013). Inicialmente, nos casos de enxertos osteocondrais, devido à própria intervenção cirúrgica, é esperado que o edema ósseo subcondral seja observado ao exame de RM e que este se resolva após a incorporação do enxerto (Trattnig et al. 2011). Entretanto, em situações clínicas, o edema ósseo pode ocorrer pela perda da integridade da cartilagem articular ou contusões articulares, e constitui a expressão de algumas alterações histológicas como fibrose, necrose, hemorragia óssea e micro fraturas trabeculares (Grossi et al. 2001, Rodrigues \& Camanho 2010, Yusuf et al. 2011, Lei et al. 2014). De acordo com Battaglia et al. (2011), após 5 anos do tratamento de lesão osteocondral no osso talo de humanos, $65 \%$ dos pacientes apresentaram edema ósseo subcondral e este achado estava correlacionado com menores porcentagens de tecido de reparação com cartilagem hialina. No atual estudo, acredita-se que o edema ósseo observado ao exame de RM em algumas amostras foi decorrente do processo esperado de reabsorção e remodelação desencadeado pelo tecido enxertado e pelas microfraturas ósseas ocasionadas pela indução do defeito, e não representou uma alteração importante no processo de reparação. Além disso, os aspectos macro e microscópicos destas mesmas amostras encontravam-se apropriados.

No presente estudo, não se pode afirmar sobre as características finais do enxerto, principalmente naqueles animais que demonstraram edema ósseo moderado. Porém, esta alteração pode diminuir ou desaparecer em longo prazo, sem necessariamente caracterizar um problema. As lesões no osso subcondral não são estáticas e inicialmente podem corresponder a uma resposta inflamatória aguda, contusão, edema e/ou necrose; e antes da substituição permanente pelo remodelamento ósseo, a deposição de fibrose ou tecido conjuntivo mixomatoso pode ocorrer (D'Anjou et al. 2008, Yusuf et al. 2011). Sendo assim, nos estágios iniciais, os padrões de imagem na RM apresentariam alto conteúdo de água e, posteriormente, baixo conteúdo de água. De acordo com Yusuf et al. (2011), quase todas as lesões subcondrais podem mudar de tamanho e de características ao longo de um período de 3 meses. Em um estudo reali- zado em humanos, após a utilização de enxerto osteocondral autógeno em casos de osteocondrite, constatou-se por meio da RM, que as alterações no osso subcondral como cistos, esclerose ou tecido de granulação ocorreram em até sete anos após o procedimento (Zak et al. 2014).

Conforme relatado por D'Anjou et al. (2008), as lesões do osso subcondral, que culminam no edema local, representam um importante componente da osteoartrite. E, embora a etiologia ainda não seja bem conhecida em humanos, acredita-se que as alterações na medula óssea e no osso trabecular, como fibrose e necrose, sejam os responsáveis pelas mudanças de sinal no exame de RM da articulação do joelho, e não o edema. Em cães, podem ser observados infiltrados de hematopoiese, fibrose e transformação mixomatosa em casos avançados de osteoartrite (D'Anjou et al. 2008). Contudo, neste atual estudo, não foram observados sinais anatomopatológicos de osteoartrite ou de processos degenerativos nas articulações avaliadas.

Em algumas articulações estudadas, independentemente do grupo avaliado, foi verificada a presença de líquido no fundo do leito receptor do enxerto. Trattnig et al. (2011) relataram que no exame de RM, o sinal de edema ósseo subcondral persistente e de cavidades císticas com intensidade de sinal semelhante a fluido podem sugerir uma falha na integração do enxerto. Especula-se que algumas pequenas lacunas persistentes podem existir entre o enxerto e a cartilagem original, permitindo a infiltração do fluido sinovial no osso subcondral, o que resulta em estímulo tecidual persistente (Efe et al. 2012). De acordo com Singh et al. (2007) e Bekkers et al. (2013), em alguns casos podem ocorrer cistos necróticos provavelmente devido a alterações isquêmicas no enxerto. No presente estudo, histologicamente, não foram identificadas lacunas que pudessem ocasionar o acúmulo de líquido no tecido enxertado, mesmo nos grupos com enxertos macerados. Também não foram identificadas áreas necróticas com acúmulo de líquidos.

De forma geral, na atual pesquisa observou-se que a presença de edema ósseo na região subcondral e de líquido no fundo do leito receptor não estavam necessariamente vinculadas aos aspectos macro e microscópicos inadequados, reforçando a importância da associação dos exames para se conseguir avaliar de forma consistente os enxertos osteocondrais. Além disso, pode-se ressaltar que alguns achados imaginológicos na RM, tais como efusão articular, edema ósseo subcondral, acúmulo de líquido e hiperintensidade de sinal no tecido de reparação, podem ser partes do curso normal do processo de reparação tecidual, devendo ser avaliados com cautela nos tratamentos com enxertia osteocondral.

A RM destaca-se por ser uma excelente técnica para avaliar alterações osteocondrais, porém, algumas anormalidades morfológicas da cartilagem só podem ser visibilizadas em lesões bem estabelecidas (Calvo et al. 2004). De fato, isto constituiu uma característica importante da RM na atual avaliação experimental, pois alguns detalhes a respeito da regularidade e do preenchimento da superfície articular diferiram das avaliações macro e microscópicas. Segundo Rodrigues \& Camanho (2010), a eficácia para a detecção da lesão cartilaginosa depende da técnica empregada e, principalmente, do tamanho da lesão. Nas 
fibrilações superficiais, a RM convencional apresenta baixa eficácia diagnóstica. Esta precisão é maior em lesões profundas, principalmente com mais de $50 \%$ de perda de substância cartilaginosa. No presente estudo, os achados corroboraram com os dados anteriores e as fibrilações e irregularidades discretas na cartilagem não foram detectadas nas imagens da RM; já os defeitos mais significativos demonstraram-se bem evidentes e fidedignos aos aspectos anatomopatológicos das amostras.

Neste estudo, em todos os métodos de avaliação utilizados não foram encontradas diferenças entre os grupos estudados, indicando que o tipo de enxerto ostecondral utilizado ou a adição do IGF-1 ao enxerto não influenciaram nos resultados finais. A utilização de IGF-1 como um agente terapêutico nas afecções articulares envolve algumas restrições, incluindo principalmente o tempo curto de permanência intra-articular e a escassez intrínseca de condrócitos para servir como células alvo (Madry et al. 2005). A falta de resposta ao IGF-1 dos condrócitos pode ser parcialmente atribuída a uma série de fatores, incluindo o aumento na quantidade de proteínas de ligação do IGF-1 no espaço articular, falta de nutrição do tecido enxertado, micromovimentação do enxerto ou a dose administrada (Singh et al. 2007). Além disso, em nenhum estudo com enxertos cartilaginosos foi obtido sucesso pleno na formação de um tecido com as características idênticas da cartilagem hialina normal (Kangarlu \& Gahunia 2006, Heir et al. 2012, Tiwary et al. 2013).

Algumas limitações deste estudo podem ser destacadas. 0 reduzido número de animais utilizados pode ter influenciado o alcance da significância estatística. A morte de um dos animais durante a realização do procedimento anestésico e a impossibilidade de acrescentar uma unidade no transcorrer da pesquisa, resultou na diferença do " $n$ " entre os grupos. 0 período de tempo decorrido para realização dos exames, que foi de 12 semanas após o procedimento, pode não ser o suficiente para se afirmar sobre a viabilidade definitiva dos enxertos. 0 tempo parece exercer um papel importante no aspecto das imagens da RM em relação ao processo de reparação osteocartilaginosa. As articulações operadas foram submetidas ao exame de RM imediatamente após a eutanásia, mas é provável que isto não tenha influenciado na formação das imagens. Ainda em relação ao exame de RM, houve uma dificuldade inicial de se adequar a bobina do equipamento à pequena articulação do joelho dos coelhos.

\section{CONCLUSÕES}

O exame de RM ofereceu informações complementares ao exame anatomopatológico, contribuindo para avaliação do tecido de reparação em enxertos osteocondrais na cartilagem articular do fêmur de coelhos.

Por ter contribuído com dados complementares, os achados diagnósticos demonstrados pelo exame de RM parecem não substituir aqueles fornecidos pelos exames macroscópicos e histológicos.

Por meio das imagens da RM e dos exames anatomopatológicos, foram observados resultados satisfatórios em relação ao processo de reparação dos enxertos osteocondrais autógenos na cartilagem de coelhos, independentemente do formato dos enxertos ou da adição de IGF-1.

Agradecimentos.- À FAPEMIG-Fundação de Amparo à Pesquisa do Estado de Minas Gerais e à CAPES- Coordenação de Aperfeiçoamento de Pessoal de Nível Superior, pelo auxílio financeiro.

\section{REFERÊNCIAS}

Araki D., Kuroda R., Matsumoto T., Nagamune K., Matsushita T., Kubo S., Oniki Y. \& Kurosaka M. 2013. An analysis of surface profile for cylindrical osteochondral grafts of the knee quantitative evaluation using a three-dimensional laser scanner. Knee Surg. Sports Traumatol. Arthrosc. 21:1794-1800.

Battaglia M., Vannini F., Buda R., Cavallo M., Ruffilli A., Monti C., Galletti S. \& Giannini S. 2011. Arthroscopic autologous chondrocyte implantation in osteochondral lesions of the talus: mid-term T2-mapping MRI evaluation. Knee Surg. Sports Traumatol. Arthrosc. 19:1376-1384.

Bekkers J.E.J., Bartels L.W., Vincken K.L., Dhert W.J.A., Creemers L.B. \& Saris D.B.F. 2013. Articular cartilage evaluation after trufit plug implantation analyzed by delayed Gadolinium-Enhanced MRI of Cartilage (dGEMRIC). Am. J. Sports Med. 41:1290-1295.

Bellido M., Lugo L., Roman-Blas J.A., Castañeda S., Calvo E., Largo R. \& Herrero-Beaumont G. 2011. Improving subchondral bone integrity reduces progression of cartilage damage in experimental osteoarthritis preceded by osteoporosis. Osteoarthritis Cartilage 19:1228-1236.

Blackman A.J., Smith M.V., Flanigan D.C., Matava M.J., Wright R.W. \& Brophy R.H. 2013. Correlation between magnetic resonance imaging and clinical outcomes after cartilage repair surgery in the knee. Am. J. Sports Med. 41:1426-1434.

Bodo G., Hangody L., Modis L. \& Hurtig M. 2004. Autologous osteochondral grafting (mosaic arthroplasty) for treatment of subchondral cystic lesions in the equine stifle and fetlock joints. Vet. Surg. 33:588-596.

Böttcher P., Zeissler M., Grevel V., Oechtering G. \& Maierl J. 2010. Mapping subchondral bone density of selected donor and recipient sites for autologous osteochondral transplantation in the canine stifle joint using computed tomographic osteoabsorptiometry. Vet. Surg. 39:496-503.

Calvo E., Palacios I., Delgado E., Sanchez-Pernaute O., Largo R., Egido J. \& Herrero-Beaumont G. 2004. Histopathological correlation of cartilage swelling detected by magnetic resonance imaging in early experimental osteoarthritis. Osteoarthritis Cartilage 12:878-886.

Chiang H. \& Jiang C. 2009. Repair of articular cartilage defects: review and perspectives. J. Formos. Med. Assoc. 108:87-101.

Cook J.L., Hudson C.C. \& Kuroki K. 2008. Autogenous osteochondral grafting for treatment of stifle osteochondrosis in dogs. Vet. Surg. 37:311-321.

D’Anjou M.A., Troncy E., Moreau M., Abram F., Raynauld J.P., Martel-Pelletier J. \& Pelletier J.P. 2008. Brief report Temporal assessment of bone marrow lesions on magnetic resonance imaging in a canine model of knee osteoarthritis: impact of sequence selection. Osteoarthritis Cartilage 16:1307-1311.

Dhollander A.A.M., De Neve F., Almqvist K.F., Verdonk R., Lambrecht S., Elewaut D., Verbruggen G. \& Verdonk P.C.M. 2011. Autologous matrix-induced chondrogenesis combined with platelet-rich plasma gel: technical description and a five pilot patients report. Knee Surg. Sports Traumatol. Arthrosc. 19:536-542.

Efe T., Theisen C., Fuchs-Winkelmann F., Stein T., Getgood A., Rominger M.B., Paletta J.R.J. \& Schofer M.D. 2012. Cell-free collagen type I matrix for repair of cartilage defects - clinical and magnetic resonance imaging results. Knee Surg. Sports Traumatol. Arthrosc. 20:1915-1922.

Endo J., Watanabe A., Sasho T., Yamaguchi S., Saito M., Akagi R., Muramatsu Y., Mukoyama S., Katsuragi J., Akatsu Y., Fukawa T., Okubo T., Osone F. \& Takahashi K. 2015. Utility of T2 mapping and dGEMRIC for evaluation of cartilage repair after allograft chondrocyte implantation in a rabbit model. Osteoarthritis Cartilage. 23:280-288.

Fitzpatrick N., Van Terheijden C.V., Yeadon R. \& Smith T.J. 2010. Osteochondral autograft transfer for treatment of osteochondritis dissecans of the caudolateral humeral head in dogs. Vet. Surg. 39:925-935. 
Goebel L., Orth P., Müller A., Zurakowski D., Bücker A., Cucchiarini M., Pape D. \& Madry H. 2012. Experimental scoring systems for macroscopic articular cartilage repair correlate with the MOCART score assessed by a high-field MRI at 9.4 T - comparative evaluation of five macroscopic scoring systems in a large animal cartilage defect model. Osteoarthritis Cartilage 20:1046-1055.

Grossi C.M., Marchiori E. \& Santos A.A.S.M.D. 2001. Comprometimento ósseo do joelho pós-trauma: avaliação pela ressonância magnética. Radiol. Bras. 34:155-160.

Hattori K., Uematsu K., Tanikake Y., Habata T., Tanaka Y., Yajima H. \& Takakura Y. 2007. Spectrocolorimetric assessment of cartilage plugs after autologous osteochondral grafting: correlations between color indices and histological finds in a rabbit model. Arthritis Res. Therapy 9:1-9.

Heir S., Aroen A., Loken S., Holme I.A., Engebretsen L. \& Reinholt F.P. 2012. Cartilage repair in the rabbit knee: mosaic plasty resulted in higher degree of tissue filling but affected subchondral bone more than microfracture technique. Knee Surg. Sports Traumatol. Arthrosc. 20:197-209.

Holland T.A., Bodde E.W., Cuijpers V.M., Baggett L.S., Tabata Y., Mikos A.G. \& Jansen J.A. 2007. Degradable hydrogel scaffolds for in vivo delivery of single and dual growth factors in cartilage repair. Osteoarthritis Cartilage. 15:187-197.

Jing L., Zhang J., Leng H., Guo Q. \& Hu Y. 2015. Repair of articular cartilage defects in the knee with autologous iliac crest cartilage in a rabbit model. Knee Surg. Sports Traumatol. Arthrosc. 23:1119-11127.

Kangarlu A. \& Gahunia H.K. 2006. Magnetic resonance imaging characterization of osteochondral defect repair in a goat model at 8T. Osteoarthritis Cartilage 14:52-62.

Khan I.M., Francis L., Theobald P.S., Perni S., Young R.D., Prokopovich P., Conlan R.S. \& Archer C.W. 2013. In vitro growth factor-induced bio engineering of mature articular cartilage. Biomaterials. 34:1478-1487.

Kido M., Ikoma K., Hara Y., Matsuda K., Kawata M., Umeda M. \& Kubo T. 2014. Selective visualization of rabbit knee cartilage using MR imaging with a double-contrast agent. J. Magn. Reson. Imaging. 39:1186-90.

Kim K., Lam J., Lu S., Spicer P.P., Lueckgen A., Tabata Y., Wong M.E., Jansen J.A., Mikos A.G. \& Kasper F.K. 2013. Osteochondral tissue regeneration using a bilayered composite hydrogel with modulating dual growth factor release kinetics in a rabbit model. J. Control Release 168:166-178.

Krusche-Mandl I., Schmitt B., Zak L., Apprich S., Aldrian S., Juras V., Friedrich K.M., Marlovits S., Weber M. \& Trattnig S. 2012. Long-term results 8 years after autologous osteochondral transplantation: 7T gagCEST and sodium magnetic resonance imaging with morphological and clinical correlation. Osteoarthritis Cartilage 20:357-363.

Lei Z., Feng G., Xu N., Wei Q., Liu J., Bian T. \& Zou T. 2014. Early extremity MRI findings and pathological synovial changes in antigen-induced arthritis rabbit model. J. Magn. Reson. Imaging. 39:1366-1373.

Liu S., Wu J., Liu X., Chen D., Bowlin G.L., Cao L., Lu J., Li F., Mo X. \& Fan C. 2015. Osteochondral regeneration using an oriented nanofiber yarn-collagen type I/hyaluronate hybrid/TCP biphasic scaffold. J. Biomed. Mater. Res. A 103:581-592.

Loffredo F.S., Pancoast J.R., Cai L., Vannelli T., Dong J.Z., Lee R.T. \& Patwari P. 2014. Targeted delivery to cartilage is critical for in vivo efficacy of insulin-like growth factor 1 in a rat model of osteoarthritis. Arthritis Rheumatol. 66:1247-1255.

Madry H., Kaul G., Cucchiarini M., Stein U., Zurakowski D., Remberger K., Menger M.D., Kohn D. \& Trippel S.B. 2005. Enhanced repair of articular cartilage defects in vivo by transplanted chondrocytes overexpressing insulin-like growth factor I (IGF-I). Gene Ther. 12:1171-1179.

Madry H., Orth P., Kaul G., Zurakowski D., Menger M.D., Kohn D. \& Cucchiarini M. 2010. Acceleration of articular cartilage repair by combined gene transfer of human insulin-like growth factor I and fibroblast growth factor-2 in vivo. Arch. of Orthop. Trauma. Surg. 130:1311-1322.

Martin-Hernandez C., Cebamanos-Celma J., Molina-Ros A., Ballester-Jimenez J.J. \& Ballester-Soleda J. 2010. Regenerated cartilage produced by autogenous periosteal grafts: a histologic and mechanical study in rabbits under the influence of continuous passive motion. Arthroscopy 26:76-83.

Mollon B., Kandel R., Chahal J. \& Theodoropoulos J. 2013. The clinical status of cartilage tissue regeneration in humans. Osteoarthritis Cartilage 21:1824-1833.
Muglia V.F., Simão M.N., Elias Júnior J. \& Trad C.S. 2001. Erros comuns de interpretação de ressonância magnética de joelho: como reconhecê-los e evitá-los. Radiol. Bras. 34:161-166.

Nam E.K., Makhsous M., Koh J., Bowen M., Nuber G. \& Zhang L. 2004. Biomechanical and histological evaluation of osteochondral transplantation in a rabbit model. Am. J. Sports Med. 32:308-316.

Nho S.J., Foo L.F., Green D.M., Shindle M.K., Warren R.F., Wickiewicz T.L., Potter H.G. \& Williams R.J. 2008. Magnetic resonance imaging and clinical evaluation of patellar resurfacing with press fit osteochondral autograft plugs. Am. J. Sports Med. 36:1101-1109.

Obara Y., Nakamura T., Shinmoto H., Osada N., Yamabe E., Sato K. \& Toyama Y. 2015. Time course of osteonecrosis in rabbit articular intercalated bone: line scan spectroscopic imaging and correlation with histology. Magn. Reson. Med. Sci. 14:57-64.

Orth P., Kaul G., Cucchiarini M., Zurakowski D., Menger M.D., Kohn D. \& Madry H. 2011. Transplanted articular chondrocytes co-overexpressing IGF-I and FGF-2 stimulate cartilage repair in vivo. Knee Surg. Sports Traumatol. Arthrosc. 19:2119-2130.

Pujol E., Van Bree H., Cauzinille L., Poncet C., Gielen I. \& Bouvy B. 2011. Anatomic study of the canine stifle using low-field magnetic resonance imaging (MRI) and MRI arthrography. Vet. Surg. 40:395-401.

Rodrigues M.B. \& Camanho G.L. 2010. Avaliação da cartilagem do joelho pela ressonância magnética. Revta Bras. Ortop. 45:340-346.

Rodríguez-Merchán E.C. 2012. The treatment of cartilage defects in the knee joint: microfracture, mosaicoplasty, and autologous chondrocyte implantation. Am. J. Orthop. 41:236-239.

Schub D.L., Frisch N.C., Bachmann K.R., Winalski C. \& Saluan P.M. 2013. Mapping of cartilage depth in the knee and elbow for use in osteochondral autograft procedures. Am. J. Sports Med. 41:903-907.

Sellers R.S., Peluso D. \& Morris E.A. 1997. The effect of Recombinant Human Bone Morphogenetic Protein-2 (rhBMP-2) on the healing of full-thickness defects of articular cartilage. J. Bone Joint Surg. Am. 79:1452-1463.

Siebert C.H., Schneider U., Sopka S., Wahner T., Miltner O. \& Niedhart C. 2006. Ingrowth of osteochondral grafts under the influence of growth factors: 6-month results of an animal study. Arch. Orthop. Trauma. Surg. 126:247-252.

Simank H., Sergi C., Jung M., Adolf S., Eckhardt C., Ehemann V., Ries R., Lill C. \& Richter W. 2004. Effects of local application of Growth and Differentiation Factor-5 (GDF-5) in a full-thickness cartilage defect model. Growth Factors. 22:35-43.

Singh N.K., Singh G.R., Amarpal, Kinjavdekar P., Sharma A.K., Mohanty T.R., Kumar S., Chae H.S., Yoo Y.M. \& Ahn C.N. 2007. Articular cartilage repair with autografting under the influence of insulin-like growth factor-1 in rabbits. J. Vet. Med. A Physiol. Pathol. Clin. Med. 54:210-218.

Singh N.K., Singh G.R., Jeong D.K. \& Lee S.J. 2013. Healing of full-thickness articular cartilage defects treated with cultured autologous chondrogenic satellite cells isolated from chondral stem cell niche in rabbits. J. Surg. Res. 183:629-638.

Thiede R.M., Lu Y. \& Markel M.D. 2012. A review of the treatment methods for cartilage defects. Vet. Comp. Orthop. Traumatol. 25:263-272.

Tiwary R., Pal A., Aithal H.P., Kinjavdekar P., Pawde A.M. \& Singh R. 2013. Effect of IGF-1 and uncultured autologous bone-marrow-derived mononuclear cells on repair of osteochondral defect in rabbits. Cartilage 5:43-54.

Trattnig S., Winalski C.S., Marlovits S., Jurvelin J.S., Welsch G.H. \& Potter H.G. 2011. Magnetic resonance imaging of cartilage repair: a review. Cartilage 2:5-26.

Van Caelenberg A.I., De Rycke L.M., Hermans K., Verhaert L., Van Bree H.J. \& Gielen I.M. 2011. Low-field magnetic resonance imaging and cross-sectional anatomy of the rabbit head. Vet. J. 188:83-91.

Yusuf E., Kortekaas M.C., Watt I., Huizinga T.W.J. \& Kloppenburg M. 2011. Do knee abnormalities visualised on MRI explain knee pain in knee osteoarthritis? A systematic review. Ann. Rheum. Dis. 70:60-67.

Zak L., Krusche-Mandl I., Aldrian S., Trattnig S. \& Marlovits S. 2014. Clinical and MRI evaluation of medium- to long-term results after autologous osteochondral transplantation (OCT) in the knee joint. Knee Surg. Sports Traumatol. Arthrosc. 22:1288-1297. 